\title{
A Escola Austríaca de Economia na História do Pensamento Econômico
}

\author{
The Austrian School of Economics in the History of the Economic Thought \\ La Escuela Austriaca de Economía en la Historia del Pensamiento Económico
}

\author{
Rodrigo Braian Nori* \\ Marcel Pereira Bernardo** \\ Leandro Garcia Meyer***
}

\author{
Palavras-chave: \\ Escola Austríaca, \\ História Econômica, \\ Liberalismo \\ Econômico, \\ Ciência Econômica.
}

\section{Keywords:}

Austrian School, Economic History, Economic Liberalism, Economic Science.

\section{Palabras clave:}

Escuela Austríaca, Historia Económica,

Liberalismo

Económico,

Ciencia Económica.

\begin{abstract}
Resumo: O presente artigo tem como finalidade investigar algumas contribuições à teoria econômica feitas pelos principais economistas da Escola Austríaca, desde seus precursores, com os escolásticos de Salamanca, até os aportes de F. A. Hayek. Para tanto, buscou-se referências em arcabouços teóricos, utilizando a metodologia de consulta bibliográfica em livros, artigos e outros meios que propagam os princípios da Escola Austríaca. O estudo foi estruturado de forma a primeiramente examinar os precursores da moderna Escola Austríaca, posteriormente, as contribuições de Carl Menger, através do marginalismo e subjetivismo metodológico; Böhm-Bawerk, com a teoria de capital e juros na cadeia produtiva e suas considerações sobre preferências temporais; Ludwig Von Mises, com o debate da impossibilidade do cálculo econômico em uma sociedade socialista e, por fim, os ensinamentos de F. A. Hayek e sua teoria austríaca sobre os ciclos econômicos.
\end{abstract}

Abstract: This paper aims to present some contributions to the economic theory made by the main economists from the Austrian School, since their precursors - the scholastics of Salamanca - until F. A. Hayek's contributions. Thereby we searched theoretical frameworks in literature such as books, papers and other media that propagate the Austrian School's principles. This work was designed to study those precursors at first, then the contributions of Carl Menger through marginalism and methodological subjectivism, Bohm-Bawerk with his capital theory in the productive chain and his considerations about temporal preferences, Ludwig Von Mises with his arguments on economic calculation impossibility in a socialist society and finally the teachings of F. A. Hayek and his Austrian theory about economic business cycles.

\begin{abstract}
Resumen: El presente artículo tiene como finalidad investigar algunas contribuciones a la teoría económica hechas por los principales economistas de la Escuela Austriaca, desde sus precursores, con los escolásticos de Salamanca, hasta los aportes de F. A. Hayek. Para ello, se buscó referencias en arcos teóricos, utilizando la metodología de consulta bibliográfica en libros, artículos y otros medios que propagan los principios de la Escuela Austriaca. El estudio fue estructurado de forma a primero examinar los precursores de la moderna Escuela Austriaca, posteriormente, las contribuciones de Carl Menger, a través del marginalismo y subjetivismo metodológico; Böhm-Bawerk, con la teoría de capital e intereses en la cadena productiva y sus consideraciones sobre preferencias temporales; Ludwig Von Mises, con el debate de la imposibilidad del cálculo económico en una sociedad socialista y, por último, las enseñanzas de F. Hayek y su teoría austriaca sobre los ciclos económicos.
\end{abstract}

DOI https://doi.org/10.30800/mises.2019.v7.1115

* Acadêmico em Ciências Econômicas pela UENP. E-mail: rodirogbraianori@hotmail.com

** Economista formado pela UNINOVE. E-mail: marcelleal05@gmail.com

*** Doutor em Economia Aplicada pela ESALQ/USP. E-mail: leandro.meyer@gmail.com 


\section{Introdução}

É possível observar nas universidades e nos diversos meios de comunicação um crescente interesse sobre a abordagem proposta pela Escola Austríaca para a investigação de problemas econômicos, políticos e sociais, quer sejam eles de natureza acadêmica, quer sejam concernentes ao debate público. Em 2008, por exemplo, houve um crescente interesse por novas abordagens que pudessem explicar os processos econômicos que desencadearam a crise do subprime, crise que teve grande impacto na economia norte americana e mundial. A perplexidade de muitos economistas frente ao cenário que se apresentava estava evidente e a busca por respostas alternativas recolocou a Escola Austríaca de economia como uma das principais correntes de pensamento capazes de explicar os fatos observados.

Considerar tal aumento de interesse como um ressurgimento está associado ao estrondoso sucesso de John Maynard Keynes nos anos 1930, que fez parecer que a Escola Austríaca estava fadada ao esquecimento. O trabalho de Lord Keynes, A Teoria Geral do Emprego, do Juro e da Moeda (1936), teve grande repercussão, tanto dentro da academia quanto entre os economistas mais próximos dos formuladores de políticas públicas e, durante as décadas seguintes, foi possível constatar que suas propostas foram as mais influentes, ao menos do ponto de vista político ${ }^{1}$. De acordo com Kirzner (1987), apenas na década de 1970 a doutrina austríaca teve maior repercussão tanto no meio acadêmico quanto no meio político. O descrédito da teoria macroeconômica keynesiana, bem como a atribuição do Prêmio Nobel de Economia para F. A. Hayek em 1974, renovaram o impulso internacional no desenvolvimento dos postulados austríacos.

Nos anos recentes, o ressurgimento do interesse na Escola Austríaca dá sinais de maior vigor, havendo uma compreensão mais aprofundada e difundida de suas ideias e uma grande profusão de análises conjunturais que se revelam bastante compatíveis com aquilo que se observa na realidade econômica. Dessa forma, boa parte do interesse sobre a abordagem da Escola Austríaca a respeito dos fenômenos econômicos é atendida por uma quantidade abundante de informações disponíveis, uma vez que há uma vasta literatura já elaborada pelos autores desta escola de pensamento, assim como uma grande diversidade de artigos que apresentam ou aplicam tais ideias (DE SOTO, 2010). Nota-se, porém, que essas informações geralmente não estão disponíveis de forma sistemática, de tal maneira que a evolução histórica das ideias da Escola Austríaca e sua relação com as demais escolas de pensamento são menos abordadas. Dado este contexto, o presente artigo tem como finalidade apresentar as principais contribuições à teoria econômica feitas por alguns dos principais economistas da Escola Austríaca, traçando a continuidade e desenvolvimento teórico desta escola de pensamento desde sua pré-história, com os escolásticos de Salamanca, até as contribuições de F. A. Hayek.

\footnotetext{
${ }^{1}$ Ver Keynes vs Hayek: as origens e a herança do maior duelo econômico da História: “Nos trinta anos seguintes, administrações de ambos os tipos levaram seus novos poderes ao limite, manipulando a economia por meio de impostos e de medidas similares em uma tentativa de maximizar a prosperidade e conseguir a reeleição. A macroeconomia, o novo ramo da "ciência sombria", inadvertidamente fundada por Keynes, tornou-se um instrumento oficial do governo dos Estados Unidos." (WAPSHOTT, 2016, p.276).
} 
Com vistas a cumprir tal objetivo, o presente artigo se divide em cinco partes, além das considerações finais. A primeira trata da origem histórica do pensamento austríaco com os pensadores da Escola de Salamanca; a segunda analisa a Teoria da Utilidade Marginal de Carl Menger. A terceira trata da Teoria do Capital e Juros de Böhm-Bawerk, enquanto a quarta parte é dedicada ao argumento da Impossibilidade do Cálculo Econômico sob o Socialismo, de Mises. A sexta seção se debruça sobre a Teoria Austríaca dos Ciclos Econômicos de Hayek e, por fim, a última seção conclui a pesquisa.

\section{Os escolásticos de Salamanca}

Atribui-se geralmente o surgimento da Escola Austríaca de Economia à publicação da obra Princípios de Economia Política, de Carl Menger, em 1871. Entretanto, o pensamento do economista austríaco possui semelhanças aos Escolásticos de Salamanca e tal similaridade vai muito além da mera causalidade. Segundo Bérenguer, (1933, p. 133-335, apud DE SOTO, 2010, p. 56): “(...) no século XVI, o imperador e rei da Espanha Carlos V enviou o seu irmão Fernando I para ser rei da Áustria". E completa: “Áustria" significa, etimologicamente, "parte este do Império", Império que nessa altura compreendia praticamente a totalidade da Europa continental, com a única exceção da França, que permanecia isolada e rodeada por forças espanholas".

É por essa razão que a tradição dos escolásticos espanhóis esteve presente no território austríaco até, enfim, ganhar novo sopro e fornecer a base para a escola de pensamento econômico em questão. Jesus Huerta de Soto cita diversos escolásticos², a começar por Diego de Covarrubias y Leyva como um dos influenciadores de Menger, assim como de outros economistas austríacos:

O estudo de Covarrubias incorpora um grande volume de dados estatísticos sobre a evolução dos preços no século precedente àquele em que viveu, e foi publicado em latim com o título de Veterum collatio numismatum ${ }^{3}$. Esta obra de Covarrubias é muito significativa, não apenas por ter sido citada de maneira laudatória em séculos posteriores pelos italianos Davanzati e Galiani,

\footnotetext{
${ }^{2}$ De Soto demonstra que a tradição escolástica não se restringe ao pensamento de Menger, mas abarca grande parte do corpo teórico da Escola Austríaca. Segundo ele: "os escolásticos espanhóis do nosso Século de Ouro foram já capazes de articular o que depois viriam a ser os princípios mais importantes da Escola Austríaca de Economia, em concreto, os seguintes: primeiro, a teoria subjetiva do valor (Diego de Covarrubias y Leyva); segundo, a descoberta da relação correta que existe entre os preços e os custos (Luis Saravia de La Calle); terceiro, a natureza dinâmica do mercado e a impossibilidade de alcançar o modelo de equilíbrio (Juan de Lugo e Juan de Salas); quarto, o conceito dinâmico de concorrência entendida como um processo de rivalidade entre os vendedores (Castillo de Bovadilla e Luis de Molina), quinto, a redescoberta do princípio da preferência temporal (Martín de Azpilcueta); sexto, o efeito profundamente distorcivo que a inflação tem sobre a economia real (Juan de Mariana, Diego de Covarrubias e Martín de Azpilcueta); sétimo, a análise crítica do sistema bancário exercido com reserva fracionária (Luis Saravia de La Calle e Martín de Azpilcueta); oitavo, a descoberta de que os depósitos bancários são parte da oferta monetária (Luis de Molina e Juan de Lugo); nono, a impossibilidade de organizar a sociedade através de ordens compulsivas, por falta da informação necessária para dar um conteúdo coordenador ás mesmas (Juan de Mariana), e décimo, a tradição liberal de que toda a intervenção injustificada no mercado constitui uma violação do direito natural (Juan de Mariana). (DE SOTO, 2010, p.55)

${ }^{3}$ Uma comparação de moedas antigas.
} 
mas sobretudo por ser um dos livros citados por Carl Menger nos seus Princípios de Economia Política (DE SOTO, 2010, p.51).

Portanto, o embrião do marginalismo austríaco tem, ao menos em parte, origem no século XVI, ganhando maior notabilidade no século XIX. Além disso, muito por conta da influência de Adam Smith, John Stuart Mill e David Ricardo, a teoria do Valor Trabalho foi dominante em um primeiro momento (BRUE, 2016). Somente após a economia se tornar uma área de pesquisa independente foi que os debates se intensificaram e aprofundaram, abrindo espaço para que o marginalismo enfim pudesse se estabelecer.

\subsection{Carl Menger: marginalismo e valor subjetivo}

Carl Menger ${ }^{4}$ (1840-1921) é considerado o precursor da Escola Austríaca de Economia, pois apesar das teses da escola terem como berço a Escolástica de Salamanca, somente em Menger há de fato a solidificação das teorias econômicas supracitadas. Em 1871, o autor publicou a obra Princípios de Economia Política, contestando a então vigente Teoria do Valor Trabalho e apresentando a Teoria do Valor Subjetivo. Dessa forma, a partir da publicação dessa obra, tem início a Revolução Marginalista ${ }^{5}$, modificando significativamente a história do pensamento econômico e o entendimento sobre o valor.

Para Menger (1988, p.73): “valor é a importância que determinados bens concretos (...) adquirem para nós, pelo fato de estarmos conscientes de que só poderemos atender às nossas necessidades na medida em que dispusermos deles". No entanto, Menger distingue valor de utilidade ao categorizar bens econômicos e não econômicos ${ }^{6}$.

Uma de suas principais contribuições foi afirmar que a relação que fundamenta o valor é a necessidade de que o agente avalia ter sobre um determinado bem, e não o bem em si mesmo. Em outras palavras, é a mente humana que incorpora valor às coisas, pois os objetivos, per se, não possuem valor. $O$ pensador sintetiza:

[...] o valor não é algo inerente aos próprios bens, não é uma propriedade dos mesmos e muito menos uma coisa independente, subsistente por si mesma. O valor é um juízo que as pessoas envolvidas em atividades econômicas fazem sobre a importância dos bens de que dispõem para a conservação de sua vida e bem-estar; portanto, só existe na consciência das pessoas em questão. (MENGER, 1988 p.75)

\footnotetext{
4 “Menger nasceu em 28 de fevereiro de 1840 em Nova Sandec, na Galícia, território atualmente pertencente à Polônia. Carl estudou nas universidades de Viena (1859-1860) e Praga (1860-1863). Depois de seu doutoramento em Cracóvia, atuou primeiro como jornalista, escrevendo para os jornais (...) sobre assuntos diversos, mas nunca referentes apenas à economia" - Introdução de F. A. Hayek (MENGER, 1988, p. 4).

${ }^{5}$ De acordo com Brue (2016), o termo 'revolução marginalista' foi utilizado para nominar a descoberta do princípio da utilidade marginal decrescente por Jevons, Menger e Walras, na segunda metade do século XIX.

${ }^{6}$ Ver Menger, p.76. "O que distingue bem não econômico de bem econômico é o fato de o atendimento das necessidades humanas não depender da disponibilidade de quantidades concretas do primeiro, mas de quantidades concretas do segundo; assim sendo, o primeiro tem utilidade, ao passo que o segundo, além de utilidade, também tem para nós a importância que determinamos valor".
} 
Essa avaliação, ou juízo, acerca da importância do bem é extremamente particular, possuindo suas próprias idiossincrasias e variando de pessoa para pessoa. Assim, de acordo com Menger (1988), uma mesma mercadoria trará um nível de satisfação diferente para cada agente, e um agente busca um fim que não necessariamente seja o mesmo do outro, mesmo que ambos desejem a mesma mercadoria. Isso não significa dizer que cada agente é uma ilha em si mesmo, e é inegável que o homem é fruto do meio em que vive. Todavia não se pode descartar que cada indivíduo possui características próprias e distintas não só físicas, mas também psicológicas. Mesmos agentes inseridos em um mesmo contexto social irão valorar os bens de forma distinta, cada qual segundo a interpretação da importância que este bem possui para a satisfação de suas necessidades.

Portanto, considerando a sociedade como um molde, o qual é igual para todos, cada indivíduo é influenciado de maneira específica, e isso se reflete na valoração dos bens, dentre outras coisas. É dessa noção que surge o caráter subjetivista do valor, gerando uma gama infinita de possibilidades e riqueza no detalhamento quanto ao fenômeno econômico do valor. A mente humana incorpora valor às coisas e cada ser possui uma mente distinta. Por isso não faz sentido, segundo a exposição mengeriana, falar em valor social, tampouco traçar uma medida de valor comum - como, por exemplo, o trabalho - para todas as mercadorias, pois esta medida, conforme Menger, também é subjetiva. Dessa maneira, ele rebate a tese de que o trabalho possa ser essa medida:

Não há nexo causal necessário e direto entre a medida do valor do bem em pauta e a quantidade maior ou menor (ou nula) de trabalho, ou de outros bens de ordem superior, que foi necessária para produzir o referido bem (...). O valor de um diamante independe totalmente de ter sido encontrado por acaso ou ser o resultado de 1000 dias de trabalho em um garimpo. Com efeito, quando alguém faz avaliação de um bem, não investiga a história da origem do mesmo, mas se preocupa exclusivamente em saber que serventia tem para ele, e de que vantagens se privaria não dispondo dele. Eis por que, não raro, certos bens que custariam muito trabalho não têm valor algum; em outros casos, bens que não custaram trabalho algum detêm alto valor (...), portanto, pode acontecer que as quantidades de trabalho ou de outros meios necessários para a produção de um bem não constituam fator decisivo para o valor do mesmo. (MENGER, 1988, p.94)

Igualmente contestada é a teoria do custo. Para Menger, não são os bens de ordem superior (matéria-prima, equipamentos, mão de obra, etc) que determinam o valor dos bens de ordem inferior ou de primeira ordem (mais próximos do consumo imediato), mas exatamente o oposto. É baseando-se no valor previsível dos bens de ordem inferior que o valor dos bens de ordem superior é ajustado, onde ele diz:

Este valor previsível dos bens de ordem inferior (...) não raro é muito diferente do valor que os bens similares têm para nós no momento atual; eis por que o valor dos bens de ordem superior - por meio dos quais dispomos dos bens de ordem inferior somente com referência a um tempo futuro - não é medido pelo valor que os referidos bens têm no momento atual, mas pelo valor que terão no momento em que forem utilizados os respectivos bens de ordem inferior. (MENGER, 1988, p.97). 
Cabe observar que tal relação valorativa entre bens presentes (de ordem superior) e bens futuros (de ordem inferior) irá influenciar Böhm-Bawek em sua obra Teoria Positiva do Capital (1888), a desenvolver sua Teoria do Capital e da Preferência Temporal, que será exposta na seção seguinte.

Uma vez exposta sua teoria subjetiva do valor, Menger aprofunda sua análise partindo para a investigação dos processos de troca de mercadorias. O economista austríaco afirma que a lógica das relações de troca consiste na desigualdade valorativa dos bens a serem trocados e não na sua equivalência. Trocar bens de valor equivalente seria, conforme Menger, impossível, uma vez que não haveria ganho ou vantagens na troca. $\mathrm{O}$ agente A só estará disposto a negociar com B, abrindo mão do bem que possui, se enxergar, segundo sua própria análise subjetiva, maior valor no bem detido por B. Por sua vez, B também deve estabelecer tal relação para que a negociação se concretize ${ }^{7}$.

O valor, por sua vez, irá balizar a negociação entre os agentes e, consequentemente, terá efeitos no sistema de preços. O preço dos bens flutua dentro da margem estabelecida entre os negociantes. Na relação de troca simples, cada agente atribui menor valor ao que possui e maior valor ao que deseja possuir, portanto os interesses convergem e a negociação é concretizada ao chegar em um ponto comum ${ }^{8}$. Eis a descrição na troca isolada. Carl Menger também descreve o sistema de preços em um cenário monopolístico ${ }^{9}$. Nesse ponto, Menger ressalta que o preço irá variar dentro da margem valorativa, tanto do vendedor quanto do comprador, mas essa margem se torna cada vez menor na medida em que entram em disputa mais concorrentes pela aquisição do bem, fixando-se mais próximo da medida oferecida por aquele comprador que apresenta mais condições ou maior disposição na transação. Sua análise prossegue com exemplos onde o aumento da quantidade ofertada pelo monopolista fará o preço diminuir, mas ainda terá poder para fixar preços mais próximos do nível valorativo mais elevado, estando à disposição somente daqueles compradores que detêm maior poder de compra para efetuar a troca. Já no caso de concorrência, mais produtos são oferecidos ao mercado, fazendo com que o bem em questão se torne mais acessível para a população, pois, conforme afirma Menger, aumentar o bem ofertado irá também aumentar o consumo ${ }^{\mathbf{1 0}}$ :

Por sua natureza, o monopolista se empenha em tornar seu produto acessível apenas às camadas superiores da população, fechando as portas aos consumidores de renda mais baixa, pois geralmente é muito mais vantajoso para ele, ou, de qualquer forma, é sempre mais cômodo auferir grandes proveitos em quantidades pequenas, que auferir pequenos proveitos com quantidades grandes. Ao contrário, a concorrência (...) tende a fazer chegar seus produtos às camadas mais baixas, tanto quanto a situação econômica permitir. $\mathrm{O}$ monopolista, dentro de certos limites, dispõe do poder de controlar os preços, ou, então, as quantidades colocadas no mercado, renunciando espontaneamente ao lucro pequeno, possível de ser obtido vendendo bens destinados ao consumo das camadas mais baixas, a fim de poder auferir proveitos maiores das camadas mais abastadas. Ao contrário, em regime de concorrência (...) o lucro mínimo é desejado por todos os concorrentes,

\footnotetext{
$\overline{7}$ Ver Menger (1988, p.113).

${ }^{8}$ Ver Menger (1988, p.123).

${ }^{9}$ Ver Menger (1988, p. 125-128).

${ }^{10}$ Ver Say $(\underline{1985, \text { p.137-143) }}$.
} 
sendo que nenhum deles está disposto a abrir mão das oportunidades que se lhes oferecem para isso. Além disso, a concorrência leva à produção e larga escala, caracterizando-se pela tendência a muitos lucros pequenos e alto grau de economicidade. Com efeito, quanto menor for o lucro em cada produto individual, tanto mais perigoso se torna qualquer desperdício antieconômico, e quanto mais intensa for a concorrência, tanto menor será a possibilidade de continuar a gerir negócios despreocupadamente, com métodos antiquados. (MENGER, 1988, p.141).

Pode-se extrair dois pontos implícitos: a) a presença de agentes com maior poder de mercado, cuja influência na formação dos preços é determinante e b) a concorrência como processo de constante descoberta, incentivando os produtores a aprimorarem seus métodos de produção, sendo este segundo aspecto desenvolvido mais detalhadamente por F. A. Hayek $^{11}$. Um terceiro aspecto, este já não implícito, é sobre como a Lei da Utilidade Marginal se aplica tanto à valoração subjetiva, quanto na formação dos preços, uma vez que a variação na quantidade de bens irá afetar a disposição de aquisição dos agentes, ou seja, quanto menos escasso é um determinado bem, menor será o valor e, igualmente, menor será seu o preço. Ao passo que maior escassez se traduzirá em maior valor e maior o preço. Com isso, o paradoxo da água e diamante ${ }^{12}$ estabelecido na teoria clássica por Adam Smith foi, enfim, superado pela Ciência Econômica.

\section{Böhm-Bawerk: teoria do capital e juros}

Eugen Böhm Ritter von Bawerk ${ }^{13}$ (1851-1914) é considerado um dos maiores expoentes do Marginalismo, sendo o mais proeminente seguidor de Carl Menger. Sua contribuição à Teoria do Capital e Juros é considerada das mais profundas e ricas da Ciência Econômica. Conforme Knut Wicksell (1986, p.113): “Somente quando Böhm-Bawerk publicou sua grande obra é que tivemos uma teoria da natureza e funções do capital, da origem e da determinação dos juros que, com uma exposição clara e exaustiva, satisfaz os gostos mais exigentes".

Böhm-Bawerk aplica a Lei da Utilidade Marginal ao capital, discernindo, tal qual Menger, os bens de ordem superior e bens de primeira ordem. Dessa forma, Böhm-Bawerk disseca a estrutura do capital, constatando que “(...) capital outra coisa não é senão o conjunto dos produtos intermediários que surgem nas diversas etapas indiretas que perfazem a via de surgimento indireta" (1986, p.38). Essas etapas indiretas são os meios empregados para se chegar a um determinado fim no qual o agente em questão, em vez de empregar sua força de trabalho diretamente aos recursos naturais, escolhe criar instrumentos que o auxiliem

\footnotetext{
${ }^{11}$ Em 1931, Hayek publica a obra Prices and Production, mostrando como os preços atuam em um sistema de mercado. Em 1945, o mesmo publica o paper The Use of Knowledge in Society, abordando os meios pelos quais o mercado se articula, gerando novos conhecimentos que, através de um processo evolutivo, coordena de forma descentralizada a alocação de recursos.

${ }^{12}$ Sobre o Paradoxo da água e diamante, ver Adam Smith, A Riqueza das Nações (1996, p.85-86).

13 “Eugen von Böhm-Bawerk nasceu na cidade de Brünn, Áustria, no dia 12 de fevereiro de 1851. (...) Estudou Direito na Universidade de Viena e Ciências Políticas em Heidelberg, Leipzig e Jena. Em 1881 foi designado professor de Economia na Universidade de Innsbruck, onde desenvolveu e defendeu os princípios econômicos delineados por Carl Menger e os economistas clássicos." (Teoria da Exploração do Socialismo-Comunismo, ano 2013, p. 9)
} 
no processo ${ }^{14}$. O uso de etapas indiretas auxilia na maior produção, ou, como afirma o autor “(...) o êxito maior manifesta-se em que, utilizando a via indireta, se pode conseguir mais produto com trabalho igual, ou o mesmo produto com menos trabalho" (1986, p.37). Existe, em contrapartida, uma desvantagem ${ }^{15}$, que é o alargamento temporal do processo produtivo. Em outras palavras, exige maior sacrifício de tempo para a consecução do objetivo. Esse segundo ponto será apresentado com maior detalhe quando tratarmos da formação do capital.

Não é trivial destacar que o capital, ainda na definição Bohn-bawerkiana, não é definido como fator de produção, mas sim como produto intermediário, ou seja, o elo entre as forças produtivas originárias: terra e trabalho.

Podemos, portanto, conformar-nos tranquilamente a riscar o capital da lista das forças produtivas autônomas, como já o fez há muito tempo uma parte da escola inglesa, e o fizeram mais tarde os socialistas. Só não o fizeram de modo totalmente acertado. Vêem na ação do capital apenas a ação do trabalho empregado para gerá-lo; dizem eles que o capital é um "trabalho executado anteriormente e acumulado". Isso é falso. O Capital - para mantermos a mesma maneira de falar - é trabalho acumulado, mas em parte; em parte ele é também força na Natureza, força preciosa e acumulada. Ele é o elo intermediário pelo qual as duas forças produtivas originais desenvolvem sua ação. (...)

Mas então, se a ação produtiva do capital se deve à Natureza e ao trabalho, o capital em si mesmo não é produtivo? Certamente que sim (...). Ele é "produtivo" primeiro, simplesmente por se destinar à produção de bens; é produtivo também porque, na qualidade de instrumento eficaz, concorre para o termino dos processos indiretos e rendosos de produção já iniciados; finalmente, ele é também indiretamente produtivo porque possibilita dar início a novos métodos de produção indiretos e lucrativos. Só uma coisa o capital não é: não é autonomamente produtivo, no sentido preciso em torno do qual gira exatamente a controvérsia mais importante. (BÖHM-BAWERK, 1986, p.127-128).

Após definir o que é capital, Böhm-Bawerk destrincha as formas como ele se manifesta, distinguindo capital social e capital privado, sendo o primeiro também denominado capital produtivo e o segundo, capital de ganho ${ }^{16}$. Para ele:

O hoje assim chamado capital privado é o conceito de origem. Não é tanto um ramo ou uma subespécie do conceito geral do capital, mas ele mesmo. Dele saiu como conceito mais restrito, (...) o assim chamado capital de economia nacional ou, mais corretamente, capital social. Este é materialmente um conceito totalmente independente. Em todos os aspectos essenciais (razão de definição, aplicação e alcance científicos) ele assenta em base totalmente autônoma e só se liga

\footnotetext{
${ }^{14}$ Ver Böhm-Bawerk (1986, p.35-37). Aqui, Böhm-Bawerk fornece três exemplos. Destaquemos o primeiro: um camponês que deseja água e busca diretamente na fonte, é a via direta. No entanto, há a desvantagem de não conseguir adquirir água mais do que suas mãos podem pegar. Além disso, toda vez que sentir sede, deverá se deslocar até a fonte. Uma segunda maneira é o camponês produzir um balde, assim poderá armazenar água e levar consigo, não precisando se deslocar até a fonte toda vez que sentir sede. E uma terceira forma é o camponês construir uma tubulação em forma de calha e conduzir a água da fonte até a entrada de sua casa. Essa irá ser a mais dispendiosa tanto em tempo quanto trabalho, no entanto terá mais água à sua disposição. Quanto mais indireto é o processo, mais longo é o tempo que camponês utiliza para obter água. No entanto, maiores quantidades de água ele poderá obter.

${ }^{15}$ Ver Böhm-Bawerk (1986, p.110).

${ }^{16}$ Ver Böhm-Bawerk (1986, p.93)
} 
ao conceito de capital privado por meio da relação externa e secundária de que casualmente o conjunto dos "produtos intermediários" coincide, quanto ao âmbito, com o conjunto daqueles produtos que para a sociedade no global são fonte de ganho, ou capital no sentido mais antigo. (BÖHM-BAWERK, 1986, p.93)

Como os termos já indicam, o primeiro se trata dos bens que auxiliam a produção, inclusive o dinheiro (BÖHM-BAWERK,1986, p.97). O segundo se trata do capital como renda, aqueles bens de consumo que seu detentor não utiliza, trocando-o por outros bens, como aluguel, empréstimos e os "meios de subsistência que os empresários adiantam aos seus trabalhadores (BÖHM-BAWERK,1986, p.101)". Temos aqui o ponto crucial da divergência de Böhm-Bawerk e dos socialistas quanto à teoria da exploração, ponto este a ser discutido mais à frente. Dessa maneira, o segundo termo (capital privado) engloba o primeiro (capital social).

Em sua análise, o autor aborda também as questões envolvendo a formação do capital, dizendo que:

Em Economia Política circulam três teses diferentes sobre a formação do capital. Para uma delas, o capital provém da poupança, para uma segunda, da produção, para uma terceira, dos dois elementos em conjunto. Destas três, a mais difundida é a terceira. Ela é também a correta. (1986, p. 129).

Não é a poupança sozinha porque a renúncia do consumo per se não aumenta a produção. Também não é produção de forma isolada porque produzir capital requer passar pelas etapas indiretas, o que, por sua vez, força a renúncia do consumo imediato. Aliás, o fato de BöhmBawerk considerar a poupança parte indispensável da formação do capital não sugere, em momento algum, que o mesmo tenha feito uma defesa moral dos capitalistas, como se estes fossem o símbolo da temperança e disciplina. A esse respeito, afirma o autor que (1986, p.130): "(...) quem possui uma renda anual de 1 milhão de florins e se contenta em consumir apenas 1/2 milhão, transformando em capital o outro 1/2 milhão, de forma alguma precisa ser um herói da renúncia". Não era preocupação do autor justificar moralmente o capitalismo, mas apenas evidenciar que, em sua visão, para haver capital, é preciso haver poupança aliada à produção. Dessa maneira, as forças produtivas são liberadas para transformarem terra e trabalho em produto intermediário que irá aumentar a capacidade de produzir, que nada mais é que o capital.

Ao falar do capital se baseando no surgimento das etapas indiretas, - ou roundaboutness - assim como sua formação, estabelecida em poupança e produção, Böhm-Bawerk fornece a chave para compreender o mais elementar componente da estrutura do capital: o tempo. Mas tempo, segundo Iorio (2011, p.107): "não entendido no seu sentido newtoniano, ou seja, meramente físico ou analógico, mas sim em sua concepção dinâmica subjetivista, isto é, da forma como subjetivamente sentido, experimentado e interpretado por cada agente." Ou seja, o tempo é o mesmo, um dia continua tendo 24 horas, assim como um minuto continua tendo 60 segundos, mas a maneira como nos relacionamos com o tempo possui aspectos subjetivos ${ }^{17}$.

\footnotetext{
${ }^{17}$ Em momento de euforia, o tempo parece passar mais rápido; em momentos de aflição, parece tardar a passar. Outro aspecto subjetivo é o fato de projetarmos o futuro, fazendo uso da imaginação, criando cenários e
} 
Quanto mais complexa e desenvolvida é a economia, mais etapas indiretas ela possuirá; o tempo, então, será maior para que se consiga produzir bens de primeira ordem, sendo a contrapartida o incremento do nível produtivo. Portanto, preferência intertemporal está intimamente ligada ao processo de criação do capital, uma vez que mais etapas indiretas fazem com que o consumo imediato seja postergado. Há uma troca valorativa em bens presentes e bens futuros, como Menger já afirmava ao descrever bens de ordens superiores e de primeira ordem. Como dito por Böhm-Bawerk (1986, p.269): “Bens presentes sempre têm mais valor do que bens futuros da mesma espécie e quantidade. Esse princípio é o ponto essencial e central da teoria do juro.” Eis a relação entre capital e juros. Dessa maneira, Böhm-Bawerk rebate as teorias que o juro do capital possui uma natureza no puro risco do capitalista ou na exploração do trabalho.

Outro ponto importante de sua teoria refere-se à heterogeneidade dos bens de capital. Isso significa que os diferentes estágios indiretos não irão se desenvolver sob a mesma constante. Portanto, para sincronizar esses estágios - também podendo ser entendidos como classes de maturação - é necessário o estabelecimento das preferências intertemporais dos agentes econômicos através das forças interativas do mercado. Um fator externo, como, por exemplo, intervenção nas taxas de juros via política monetária, irá alterar a preferência temporal dos agentes, fator este que coordena os diferentes estágios produtivos, criando distorções na estrutura do capital. Eis o elo para a Teoria Austríaca dos Ciclos Econômicos, elaborada primeiramente por Mises e desenvolvida por Hayek, que será exposta posteriormente.

Acreditava-se que o juro tinha sua origem no risco ao investir que o capitalista corria ao realizar seus empreendimentos. É verdade que, agindo sob incerteza em relação aos momentos futuros, todo investimento acarretará risco em maior ou menor grau. Entretanto, não é o risco per se a causa originária dos juros; sua causa é a preferência entre dispor de um bem no presente e abster de seu imediato consumo para reservá-lo a um momento futuro - quando finalmente haverá consumo. Sendo assim, a causa é o tempo puramente necessário - ou, como também se pode dizer, a preferência intertemporal - para conclusão de um dado processo e o risco é o efeito do maior ou menor tempo decorrido.

A outra controvérsia é se os ganhos de capital "que alguns denominam "juro original do capital" ou profit (lucro) e outros chamam de "mais-valia" (mehrwert) ${ }^{18}$ constituem de fato uma relação de exploração. Curiosamente, no caso de empréstimos, parece ser muito claro a relação de que o credor está abrindo mão do capital hoje - que poderia ser utilizado para consumo próprio - para entregar a terceiros, havendo, nesse processo, de acordo com a natureza temporal dos juros já explicitada aqui, uma remuneração devida por parte do tomador ao credor. Tanto no consenso popular, quanto na opinião especializada dos economistas, não há acusações de exploração nesse caso. Todavia, o conceito lógico dos ganhos de capital provenientes da preferência temporal parece simplesmente se pulverizar quando aplicado ao mercado de trabalho. É como se o mercado de trabalho fosse parte isolada da economia ou então um

tentando adaptar nossas ações presentes para chegarmos ao cenário futuro vislumbrando. Esses aspectos são observados por Böhm-Bawerk (1986, p. 270-273).

${ }^{18}$ Ver Böhm-Bawerk (1986, p.310) 
mundo paralelo cujas leis gerais da economia não penetram. Mas, mesmo aqui, a lógica dos ganhos de capital se aplica igualmente.

Igualmente curioso é o caso daqueles economistas que rejeitam a teoria do valor-trabalho, mas acreditam na mais-valia, isto é, que o valor total dos bens produzidos é devido inteiramente ao trabalhador e que qualquer ocorrência oposta a isso desemboca em exploração. A seguinte exposição tenciona evidenciar como os ganhos relativos destinados ao trabalhador ocorrem em etapas temporais distintas dos ganhos do capitalista.

Apenas para fins didáticos ${ }^{19}$, o economista austríaco usa o exemplo da construção de uma máquina a vapor ${ }^{20}$. Como já exposto, a produção do capital se divide em diversas etapas intermediárias. Recorda-se também, conforme Menger, as previsões sobre o valor bens de primeira ordem direcionam o valor dos bens de ordem superior. Portanto, em seu exemplo, a máquina a vapor possui um valor futuramente previsto - ou seja, ainda não concreto no presente - sendo este valor traduzido para o preço 5500 dólares e cuja construção só terminará em cinco anos. Aqui cabe a pergunta: quando o trabalhador deve receber sua parte? Não há condições de ele esperar até a conclusão da máquina.

Então o trabalhador, conforme o exemplo, recebe sua parte anualmente. Terminado o primeiro ano, segue então:

Qual será, no entanto, o valor desta parte do trabalho em relação ao valor da máquina pronta? Este é um ponto em que um pensador superficial pode errar facilmente. O trabalhador executou até agora um quinto do trabalho técnico exigido para a criação da máquina inteira. Consequentemente - somos tentados a concluir num pensamento superficial - seu produto atual será um quinto do valor do produto inteiro, o que corresponde, portanto, a 1100 dólares. Conclui-se, então, que o trabalhador deve recebe um salário anual de 1100 dólares.

Errado: a quantia de 1100 dólares corresponde a um quinto do valor de uma máquina a vapor pronta, atualmente; mas o que o trabalhador produziu até aqui não é um quinto de uma máquina pronta, e sim um quinto de uma máquina que só estará pronta em quatro anos. E isso são duas coisas distintas. (...)

O primeiro quinto tem um valor diferente do último quinto, da mesma forma que uma máquina completa tem, hoje, um valor diferente do de uma máquina que só estará disponível dentro de mais quatro anos. Isto é tão certo quanto o fato de que todos os bens hoje existentes têm um valor diferente daquele que têm os bens futuros. (BÖHM-BAWERK, 2013, p.69-70)

Dessa forma, Böhm-Bawerk elucida que o momento no qual ocorre a remuneração do trabalhador é distinto do momento remunerativo do capitalista. Este último adianta sua parte

\footnotetext{
${ }^{19}$ Böhm-Bawerk costuma dar exemplos sobre Robinson Crusoé ou similares, recebendo críticas da ala socialista. Conforme o autor: "A história do Robinson e descrições do estado primitivo são coisa muito boa para destacar com clareza os aspectos típicos mais simples, digamos, o esqueleto dos processos econômicos." E prossegue: "mas é claro que elas não são suficientes para nos dar uma ideia adequada (...) precisamos, portanto, fazer uma mudança de cenário: da praia solitária do nosso Robinson para o mecanismo da economia de uma grande nação com muitos milhões de habitantes." (BÖHM-BAWERK, p.132). Portanto, é errôneo supor que o economista austríaco se resume a apresentar modelos demasiados simples cuja aplicação não se enquadra no mundo real. Suas explicações sobre capital social englobam modelos mais abrangentes, complexos e sofisticados que podem ser observados nas páginas 133 até 145.
}

${ }^{20}$ Ver Böhm-Bawerk,Teoria da Exploração do Socialismo-Comunismo ( 2013, p.68-74). 
ao trabalhador, cujo valor atual é menor que o valor futuro, afinal, o trabalhador recebe sua devida quantia ainda durante o processo ao passo que o capitalista só tem sua parte quando o processo está devidamente finalizado. O exemplo da máquina a vapor dado por Böhm-Bawerk ajuda a compreender como o fenômeno do valor se comporta durante o processo produtivo. O valor não é algo dado, estático e imutável; sua manifestação, ao contrário, está intimamente entrelaçada aos fatores de preferência temporal, isto é, o valor é dinâmico pois se modifica conforme a execução dos processos produtivos avança. A conclusão de Böhm-Bawerk é de que a relação entre capital e trabalho não se baseia na exploração do primeiro pelo segundo, mas na proporcional quantia dado o estágio atual de produção. Em outras palavras, a remuneração do trabalhador deve ser compatível com o momento em que o pagamento ocorre, não sendo possível e nem lógico receber no presente o fruto dos bens futuros.

\section{Ludwig Von Mises: o cálculo econômico}

Ludwig Von Mises ${ }^{21}$ (1881-1973) sucedeu Böhm-Bawerk no desenvolvimento dos postulados austríacos. Maior expoente da Escola Austríaca de Economia, Mises possui uma extensa bibliografia no campo social, político e econômico, tendo sido autor de Human Action (1949), sua maior obra. Dentre suas inúmeras contribuições, destaca-se o que talvez tenha sido o mais emblemático debate econômico ocorrido até então, o debate sobre o cálculo econômico em uma sociedade socialista.

Em 1920, período esse em que o ideal socialista ascendia com grande receptividade, Mises publica seu artigo Economic Calculation in the Socialist Commonwealth, argumentando de forma teórica que não seria possível, em uma sociedade socialista, alocar os seus recursos de forma racional. Porém, antes de adentrar no conceito expositivo e suas implicações, é necessário estabelecer o escopo histórico das teses socialista e sua origem na economia clássica.

De acordo com Hicks (1978, p. 212, apud BARBIERI, 2013, p. 30), enquanto os economistas clássicos tinham como preocupação o estudo da produção e distribuição de riquezas, os neoclássicos se ocupavam no estudo das trocas e sua lógica sob a escassez. Como as ideias marxistas se desenvolveram no contexto clássico ricardiano, as escolhas relativas à produção não foram indagadas. Nesse sentido, o desafio de Mises está embasado justamente na teoria marxista.

Para Mises (2012), a essência do socialismo está naquilo que ele dizia ser uma espécie de negativa do capitalismo, ou seja, aquilo que o distingue é o fato de os meios de produção não estarem sob a propriedade do indivíduo, mas sim de uma [hipotética] sociedade geral. Sendo

\footnotetext{
${ }^{21}$ Nascido em na cidade de Lemberg, à época situada no interior do Império Austro-Húngaro, Mises estudou sob a tutela de Böhm-Bawerk no Seminário de Economia na Universidade de Viena. Em 1906, Mises começou a sua atividade docente, primeiro, durante seis anos, ensinando Economia na Escola feminina de estudos comerciais de Viena, e depois, a partir de 1913, como professor da Universidade de Viena. Em 1934, foi nomeado catedrático de Economia Internacional no Instituto Universitário de Altos Estudos Internacionais de Genebra, Suíça, mudando-se, fugindo de Hitler, no começo da Segunda Guerra Mundial, para os Estados Unidos, onde adquiriu a nacionalidade americana e foi nomeado professor da Universidade de Nova Iorque, posto que desempenhou até à sua jubilação em 1969. (DE SOTO, 2010, p.91-92)
} 
assim, com a propriedade privada dos meios de produção negada ao indivíduo, não há a existência de mercados, pois, nesse arranjo, os indivíduos não poderiam de maneira arbitrária explorar os recursos. Isso significa que haveria algum órgão representativo ${ }^{22} \mathrm{com}_{\text {a incumbência }}$ de gerir todos os recursos disponíveis, podendo ser este órgão o Estado socialista ${ }^{23}$ ou outra entidade coletiva. Partindo deste princípio, não haveria mais livre iniciativa uma vez que os indivíduos ficariam totalmente dependentes da permissão de seus representantes. Soma-se a isso o fato que determinado recurso só pode ser explorado por este órgão representativo, não podendo sê-lo por mais nenhum outro indivíduo ou entidade. Sendo assim, o princípio da livre concorrência também estaria seriamente comprometido. Dessa maneira, sem livre iniciativa e sem livre concorrência, não há formação genuína de mercados; sem mercados, torna-se impossível realizar formação de preços. Com a ausência de preços de mercado, cálculos de lucros e prejuízos se tornam imensuráveis e, consequentemente, não há como direcionar a utilização dos recursos escassos de maneira racional e eficiente.

O problema surge então com os bens de capital. Em uma economia de mercado, os empresários alocam recursos com base na informação contida nos preços presentes e nas expectativas sobre os preços futuros, ou seja, os preços relativos refletem abundância ou escassez, indicando o que os empresários devem ou não produzir. Porém, no sistema socialista, onde todo capital está nas mãos do Estado, não existe o mecanismo de preços. Desta maneira, alega Mises, o planejador central não consegue avaliar com precisão a escassez relativa dos bens de capital, impossibilitando a determinação de quais bens devem ser produzidos.

Os argumentos de Mises se tornaram então centro de grande debate no âmbito econômico e, desde sua formulação, economistas socialistas buscam moldar alternativas para contestá-lo. Segundo Barbieri (․13), pode-se dividir esse período em dois conjuntos de respostas:

O primeiro conjunto de respostas ao desafio de Mises foi feito ainda na década de vinte, por autores austríacos e alemães. (...) As propostas de operacionalização do socialismo discutidas nessa fase são geralmente baseadas da defesa de associações e monopólios setoriais. (...) $\mathrm{Na}$ década de trinta o debate ressurge, agora em inglês. Nessa fase, a defesa do socialismo será feita por autores filiados à teoria neoclássica e politicamente será mais próximo do fabianismo inglês, que favorece a conciliação de ideais socialistas com a democracia inglesa. Nesse debate surgiram as principais tentativas de construir um modelo de funcionamento do socialismo que ficou conhecido como socialismo de mercado e que buscava conciliar mecanismos de mercado com a abolição da propriedade privada dos bens de capital. (BARBIERI, 2013, p.89)

A característica comum às várias versões da solução socialista de mercado é que seus autores (Fred Taylor, H. D. Dickinson, Abba Lerner e Oskar Lange) pretendem utilizar o

${ }^{22}$ Ver Mises (2012, p.17). “Desnecessário dizer que a comunidade só estará apta a empregar esses poderes através da criação de um corpo especial para esta finalidade. A estrutura deste corpo e a maneira como ele irá articular e representar o desejo da comunidade é, para nós, de importância secundária. Pode-se pressupor que esta última irá depender da escolha do corpo de funcionários ou - nos casos em que o poder não estiver assentado em uma ditadura - do voto majoritário dos membros da corporação".

${ }^{23}$ Sabe-se que historicamente a entidade representativa na maioria das sociedades socialistas foi o Estado. Tratar-se-á, portanto, no presente artigo, desta instituição para facilitar a exposição do tema. 
modelo de equilíbrio neoclássico e, através do processo de tentativa e erro, criar uma espécie de quase mercado, em que os agentes econômicos teriam comportamentos parecidos com os que teriam em uma economia capitalista. $\mathrm{O}$ argumento geral é que poderia existir certo grau de competição entre uma série de monopólios ou trustes que, sob o controle dos sindicatos ou do Estado, seriam uma espécie de espinha dorsal para a organização econômica do socialismo. Esse sistema funcionaria com o Estado escolhendo preços arbitrários (paramétricos) para os bens de consumo e de capital e, através desses preços, os administradores estatais então devem produzir até o momento em que o custo marginal de cada bem final seja igual a seu preço.

Tal argumento é rebatido pelo fato de que os preços estabelecidos pelo Estado não refletirão necessariamente a escassez real dos recursos mesmo que a intenção seja se aproximar dos preços praticados normalmente no mercado. Inclusive, sobre o Estado se basear no histórico dos preços de mercado, Mises afirma" " "Por algum tempo, a memória da experiência adquirida com a economia competitiva (...) poderia adiar um pouco o completo colapso da economia." E complementa: "Os antigos métodos de procedimento poderiam ser mantidos, não por causa de sua racionalidade, mas porque aparentariam já estarem consagrados pela tradição”. $\mathrm{O}$ economista austríaco também considera ser irrelevante um industrial saber qual era o preço do produtivo que ele vende há décadas atrás se o essencial é verificar não o histórico dos preços, mas sim as condições atuais da economia. Sua teoria sobre a importância da propriedade privada para manter a racionalidade econômica pode ser confirmada quando Joseph Stalin estatizou a produção agrícola da Ucrânia no início dos anos 1930, criando, assim, as Fazendas Coletivas. Nesse mesmo ano, estima-se que sete milhões de pessoas morreram pela fome, em um episódio conhecido como Holodomor ${ }^{25}$. Além disso, no decorrer da experiência socialista na União Soviética, a escassez generalizada de produtos essenciais foi persistente. Vale ressaltar que o sistema econômico soviético durou de 1917 até 1991, ou seja, apenas 74 anos, menos que a atual expectativa média de vida brasileira ${ }^{26}$, ajudando a comprovar a tese de Mises sobre a não durabilidade do socialismo.

Embora diversos modelos tenham sido formulados ao longo do debate, todos apresentavam simplificações que distanciam as propostas dos reais problemas alocativos. Conforme Barbieri (2013, p. 284): “O debate do cálculo, além das discussões sobre a natureza do problema em si e das interpretações dos argumentos utilizados, girou em torno da viabilidade dessas propostas”. E completa: “(...) o desafio original de Mises continua sem resposta. Todas as tentativas de refutar seu argumento só tiveram sucesso na medida em que conseguiram distorcer o problema original ${ }^{27}$."

\footnotetext{
${ }^{24}$ Ver Mises (2012, p.30)

${ }^{25}$ Anne Applebaum dedica uma obra inteira ao tema, intitulada Red Famine (2017).

${ }^{26}$ Conforme IBGE, a expectativa de vida média é 75 anos. (IBGE, 2012)

${ }^{27}$ Ver Barbieri (2013, p. 10).
} 


\section{Friedrich August Von Hayek: Teoria Austríaca dos ciclos econômicos}

F.A. Hayek ${ }^{28}$ (1899-1992) é o mais famoso pensador da Escola Austríaca ${ }^{29}$, desenvolvendo trabalhos em outras áreas além da economia, como, por exemplo, Filosofia do Direito, Filosofia Política, Epistemologia e Psicologia. Especificamente na economia, a maior contribuição é sua Teoria dos Ciclos Econômicos, que lhe rendeu Prêmio Nobel em 1974. Vale destacar o reconhecimento tardio de sua contribuição à ciência econômica, uma vez que tal teoria foi desenvolvida no final dos anos 1920. Foi por conta da elaboração dela que Hayek, com apenas 31 anos, foi convidado por Lionel Robbins a lecionar na London School of Economics e rivalizar com as teorias da Universidade de Cambrigde acerca do que de fato havia ocorrido em 1929, cujo maior expoente era John Maynard Keynes.

Ancorando-se no conceito de heterogeneidade do Capital de Böhm-Bawerk ${ }^{30} \mathrm{e}$ nos estudos sobre taxas de juros natural e monetária de Knut Wicksell ${ }^{31}$, Hayek percebeu que os boons causados pela expansão da oferta monetária carregavam as sementes da crise, configurando ciclos econômicos.

(...) Hayek salientou que as flutuações cíclicas podem ser provocadas por fatores monetários, isto é, por aumento da oferta de moeda não lastreados em poupança e que o fenômeno das flutuações, embora tendo causas monetárias, manifesta-se por alterações no setor real da economia, em sua estrutura real de produção ou estrutura de capital. (...) Hayek mostrou serem diferentes os impactos de uma queda na taxa de juros causados por aumentos na oferta de moeda e no aumento da poupança: os primeiros provocam flutuações cíclicas, os segundos não; os primeiros são maléficos, enquanto os segundos são benéficos. Esses impactos de uma expansão monetária não lastreada em poupança sobre a estrutura de produção da economia podem ser chamados de efeito taxa de juros. (IORIO, 2010, p.175).

Conforme Ubiratan Jorge Iorio ${ }^{32}$, a TACE (Teoria Austríaca dos Ciclos Econômicos) pode ser compreendida em cinco estágios: 1) boom da economia via expansão da oferta monetária; 2) aumento da renda e seus efeitos sobre a economia real;3) aperto do crédito ocasionado pela disputa de demanda por bens de consumo e bens de capital; 4) recessão; e, finalmente, 5) o início da recuperação da economia, expurgando os investimentos errôneos (malinvestments).

\footnotetext{
28 "Nascido em Viena, em 8 de maio de 1899, Hayek foi sem dúvida favorecido por seu ambiente intelectual. Conheceu, por exemplo, o grande economista Eugen von Böhm-Bawerk, amigo do seu avô, bem antes de ter aprendido o significado da palavra "economia". Não foi nada surpreendente que tenha ingressado na Universidade de Viena e, menos ainda, que tenha obtido dois doutorados, um em Direito (1921) e outro em Ciências Políticas (1923)." (BUTLER, 1987, p.6)

${ }^{29}$ Bouttke $(2012$, p.3).

${ }^{30} \mathrm{O}$ ponto central desse estudo é fazer uma pesquisa sistemática sobre as interrelações entre diferentes partes da estrutura material do processo de produção e das condições de mudanças. Na medida que esses problemas complexos foram explicitamente discutidos no passado, eles foram tratados como parte da teoria do capital e juros. (HAYEK, 1950, p.3)

${ }^{31}$ Enquanto me parece que a análise sobre os efeitos de uma taxa monetária de juros divergindo de uma taxa natural, Professor Mises fez considerável progresso em comparação com a posição adotada por Wicksell, que depois sucedeu-se melhor que Mises na explicação da origem dessa divergência. (HAYEK, 2008, p.76)

${ }^{32}$ Ver Iorio (2011, p.160-166).
} 
Basicamente, pode-se entender esses estágios da seguinte forma: a redução das taxas de juros via política monetária expansionista irá aquecer a economia no curto prazo. Investimentos são iniciados, levando a um aquecimento da economia. Com os incentivos liberados, há procura simultânea por bens de consumo e bens de capital e o PIB tende a crescer. Posteriormente, a expansão de crédito mostrará seu efeito colateral: a inflação. Como a oferta possui relação direta aos preços, o aumento contínuo de preços estimula o crescimento da oferta. Todavia, em um primeiro momento, o aumento de preços refletia a demanda efetiva; em um segundo estágio, o aumento de preços é apenas o efeito de uma bolha inflacionária. Fazer a leitura precisa do que está havendo na economia, identificando o que de fato é efeito da demanda e o que é apenas efeito inflacionário é uma tarefa difícil e, mesmo havendo a leitura correta, os produtores não poderão mais voltar atrás, uma vez que projetos de longo prazo (produção de bens de capital) muitas vezes já foram iniciados. Pelo lado da demanda, sendo sua relação inversa ao preço, a presença da inflação acarretará em perda do poder de compra da moeda. Assim, tem-se de um lado uma oferta estimulada e de outro uma demanda sufocada.

Daí nasce o problema da superprodução que, na visão austríaca, não é causado pelo animal spirits dos capitalistas como John Maynard Keynes argumentara, e sim pela intervenção estatal nas taxas de juros, modificando a preferência intertemporal dos agentes e, consequentemente, a estrutura do capital (poupança + investimentos). Sendo o juro o preço futuro do capital, e sendo o preço a informação fornecida aos agentes, toda intervenção no sistema de preços causará distorções na interpretação sobre o nível de escassez dos recursos. Nesse caso, o nível de escassez da poupança necessária para dar suporte ao aumento dos investimentos. Esse cenário inflacionário de oferta estimulada versus demanda sufocada fará com que a produção não tenha para onde ser escoada, levando a demissões e quebradeira. Paralelamente ao aumento do desemprego, ainda pode ser observada a presença da inflação. Para Hayek, os projetos insustentáveis (malinvestments) devem ser expurgados do mercado. Eis a autocorreção da economia. O emprego nos períodos de curto e médio prazo só era mantido graças à inflação e não por causa do dinamismo e fortalecimento da capacidade da economia. Somente quando esses malinvestments forem completamente encerrados, a economia poderá voltar a crescer de maneira sustentável e estável no longo prazo.

Outro aspecto da teoria hayekiana é a não neutralidade da moeda, uma vez que a variação na quantidade de moedas não só afetará o setor real da economia, como também causará alterações disformes ao longo dos diversos estágios de produção. “De acordo com o princípio da neutralidade da moeda, então, a estrutura de produção sofreria alterações uniformes ao longo da cadeia produtiva" (IORIO, 2011, p.167). E prossegue ele "As variações nas taxas de juros afetam a economia de uma forma desigual ao longo da estrutura de produção. Isso não é considerado pelos modelos macroeconômicos, em que mudanças na taxa de juros afetam toda a economia por igual, de modo uniforme ${ }^{33 \prime \prime}$.

A Teoria Austríaca dos Ciclos Econômicos pode ser aplicada para compreender momentos como a crise de 1929, a crise de 2008 e a crise de 2015 e 2016 no Brasil, para citar apenas alguns casos. De acordo com Hayek, os ciclos se iniciam com a expansão de crédito. Conforme dados

${ }^{33}$ Idem p. 178. 
da Federal Reserve ${ }^{34}$, de 1921 até 1927, houve redução das taxas de juros de 6\% a 3,5\%, ou seja, uma redução superior a 41\% em apenas 6 anos e, em 1929, veio a crise.

Em 2001, a mesma política de redução de juros para estimular a economia foi tomada pela Federal Reserve ${ }^{35}$. Em relatório do próprio Federal Reserve apresentado ao Congresso Norte Americano é dito:

“The devastating events of September 11 further set back an already fragile economy. Heightened uncertainty and badly shaken confidence caused a widespread pullback from economic activity and from risk-taking in financial markets, where equity prices fell sharply for several weeks and credit risk spreads widened appreciably. The most pressing concern of the Federal Reserve in the first few days following the attacks was to help shore up the infrastructure of financial markets and to provide massive quantities of liquidity to limit potential disruptions to the functioning of those markets. The economic fallout of the events of September 11 led the Federal Open Market Committee (FOMC) to cut the target federal funds rate after a conference call early the following week and again at each meeting through the end of the year ${ }^{36 \prime \prime}$.

Foi a maior queda das taxas de juros em décadas ${ }^{37}$, caindo de mais de 5,5\% em 2001 a 1\% em 2003, e se mantendo neste patamar até 2005. A economia experimentou sua fase de boom, mas em 2007, a economia já dava sinais de crise e em 2008, veio a recessão.

Segundo Iorio (2011, p. 171): “Nos anos recentes, especialmente devido à crise que se manifestou em 2008 na economia norte-americana e que se alastrou pelo mundo inteiro, tem ocorrido um renovado interesse em torno do tema das flutuações cíclicas, o que não ocorria desde os anos 1930". De fato, períodos de crise incentivam a busca por novas explicações ou até mesmo a reconsideração de teorias que se encontravam em desuso. Não coincidentemente, a Escola Austríaca ganhou impulso após esse conturbado período.

No caso recente do Brasil, conforme demonstra a pesquisadora do IPEA, Monica Mora (2015): “O crédito aumentou (...) inclusive após a crise de 2008. Assim, o volume de crédito, que representava $26 \%$ do produto interno bruto (PIB), em dezembro de 2002, atingiu 45,2\% do PIB, em dezembro de 2010." Isto é, houve agressiva expansão de crédito. Entre 2012 e 2013, a economia brasileira teve as menores taxas de juros da série histórica até aquele momento ${ }^{38}$. Em 2014, a taxa de juros voltou a subir, atingindo dois dígitos, e em 2015 e 2016 foi registrada

\footnotetext{
${ }^{34}$ FED. Disponível em: https://fred.stlouisfed.org/graph/fredgraph.png?g=cdSb. Acesso em: 08/04/2018

${ }^{35}$ FED. Disponível em: https://www.federalreserve.gov/boarddocs/hh/2002/February/FullReport.pdf. Acesso em: 8 abril 2018.

${ }^{36}$ Os eventos devastadores de 11 de setembro atrasaram ainda mais uma economia já frágil. A incerteza aumentada e a confiança abalada causaram um retrocesso generalizado da atividade econômica e da tomada de riscos nos mercados financeiros, onde os preços das ações caíram acentuadamente por várias semanas e os spreads de risco de crédito aumentaram sensivelmente. A preocupação mais premente do Federal Reserve nos primeiros dias após os ataques foi ajudar a fortalecer a infraestrutura dos mercados financeiros e fornecer enormes quantidades de liquidez para limitar possíveis interrupções no funcionamento desses mercados. As consequências econômicas dos eventos de 11 de setembro levaram o Comitê Federal de Mercado Aberto (FOMC) a cortar a taxa básica de juros após uma teleconferência no início da semana seguinte e novamente em cada reunião até o final do ano.

${ }^{37}$ FED. Disponível em: https://fred.stlouisfed.org/graph/fredgraph.png?g=jcUs. Acesso em: 10 abril 2018.

${ }^{38}$ BCB. Disponível em: https://www.bcb.gov.br/Pec/Copom/Port/taxaSelic.asp. Acesso em: 10 abril 2018.
} 
uma das piores recessões da história do país. Conforme os três exemplos, houve redução das taxas de juros por um longo período e aumento nos anos que antecederam a recessão.

Tomemos o caso de uma expansão na oferta de moeda. Ela reduz a taxa de juros, o que aumenta o grau de roundaboutness, isto é, acontece um alargamento da estrutura de produção. Com isso, os preços dos bens finais irão subir comparativamente aos preços dos bens mais distantes do consumo final, o que elevará os rendimentos nos setores produtores dos primeiros e provocará, assim, a redução no grau de roundaboutness. Hayek denominou isto(...) de efeito Ricardo que, em sua formulação original, referia-se à substituição de mão-de-obra (fator de produção de curto prazo) por capital (fator de produção de longo prazo), em decorrência de uma redução nas taxas de juros. Mas, para Hayek e os austríacos, a substituição relevante não é entre "homem" e "máquina", mas entre bens de capital de ordens menos elevadas e de ordens mais elevadas ao longo da estrutura de capital (IORIO, 2011, p.180).

A elevação nas taxas de juros reflete 1) o movimento natural do mercado frente à redução artificial dos juros, isto é, juros baixos sem que haja lastro correspondente no aumento da poupança. Pelo fato de os agentes acharem que possuem poupança suficiente e correspondente ao nível dos juros baixos praticados, há um excesso de demanda por fundos que não pode ser sustentável a longo prazo. Em outras palavras, os agentes acham que possuem mais poupança que de fato têm e contam com um nível de poupança que não existe e 2) o esgotamento da poupança que se encontrava abaixo do nível adequado para que se pudesse expandir os investimentos via aumento da oferta de crédito conduz à recessão. Quando isso ocorre, os projetos iniciados no momento do boom não encontram meios de se sustentar. No entanto, não é a elevação das taxas de juros que desencadeia a recessão, pois antes de haver o aumento, a crise já está em andamento. Sua elevação é a resposta do mercado para que haja abstinência do consumo imediato, reconstruindo o nível de poupança necessário.

O efeito Ricardo produz, então, um impacto inicial de aumentar o produto (embora o nível de investimento não mude), mas produz o fenômeno do capital shallowing ou efeito concertina (...). O efeito concertina refere-se, portanto, ao fato de que a poupança forçada incentiva inicialmente métodos de produção mais indiretos, mas, após algum tempo, os investimentos acabam sendo realocados para os métodos menos indiretos, fazendo com que a estrutura de capital "estique" e "encolha", tal como uma sanfona. No final das contas, o estoque de capital "agregado" ou capital fixo diminui. (...) Mesmo antes do aumento na taxa de juros, as subidas nas taxas de retorno fazem com que projetos investimentos de investimentos que pareciam lucrativos tornarem-se não lucrativos e serem abandonados. Quando a taxa de juros subir - o que acontecerá em decorrência da disputa pelo crédito entre os setores mais próximos e os mais afastados dos bens de consumo final - ocorrerá uma aceleração nesse processo. Adicionalmente, os efeitos da queda na renda nesses setores agora não mais lucrativos causarão queda na demanda de bens de consumo final e mais desemprego. A queda na demanda de bens intermediários da estrutura de produção, gerada pela demanda de bens finais menor, será mais um agravante. (IORIO, 2011, p.181-182).

Esses três exemplos indicam que a teoria de Hayek se sustenta, ou, ao menos, que sua teoria deveria ser alvo de intensos debates e mais atenção por parte dos economistas, sobretudo por essa teoria dos ciclos estar relacionada a uma teoria do capital, dos juros e, também, da moeda. Conforme Soromenho (1995, p.77): “(...) um ponto que não tem merecido a devida atenção é o papel da teoria wickselliana na gênese na agenda de pesquisa sobre os ciclos que seria desenvolvida por Hayek". 


\section{Considerações finais}

Viu-se as principais contribuições de cada um dos mais relevantes autores austríacos. Destaque para a Teoria do Valor Subjetivo, marco teórico conhecido como Revolução Marginalista, fornecendo considerações até hoje consideradas basilares para a compreensão do valor enquanto fenômeno econômico. Outro destaque é a abordagem de Capital sendo dividido em diversos estágios de produção indireta podendo facilitar o diagnóstico de crises e recessões. O aspecto marginalista exibe a relação de trade-off entre as ordens superiores e de primeira ordem, já que para haver bens de consumo, os estágios intermediários devem ser concluídos e isso demanda tempo (preferência temporal), conectando com a Teoria dos Juros. A escassez de recursos não permite aumento simultâneo em ambas já que maior produção de bens de capital elevará a quantidade de estágios de produção indireta, afastando temporalmente o processo da formação de bens de primeira ordem. Eis a necessidade, segundo a tradição austríaca, de poupança prévia para haver sustento do investimento e não o contrário. Recorrer à expansão da oferta monetária sem que haja lastro em poupança para sustentar o volume de dinheiro recém-criado, conforme demonstrado, poderá gerar ciclos econômicos. Outro ponto levantado é sobre a não neutralidade da moeda e como diferentes estágios de produção são afetados de modo não uniforme, assim como a velocidade da moeda não se manter constante, conforme argumenta a Teoria Quantitativa da Moeda. Por fim, a racionalidade econômica em uma sociedade complexa como a atual só é possível, conforme a Escola Austríaca, em um sistema baseado na propriedade privada e nos preços livres - isto é, praticados sem intervenção estatal -, afirmação essa que promove o debate com as escolas de pensamento de cunho socialista e intervencionista.

\section{Reeferências}

APPLEBAUM, Anne. Red Famine: Stalin's War on Ukraine. S/l: Doubleday, 2017.

BARBIERI, Fábio. História do debate do cálculo econômico socialista. $1^{\circ}$ ed. São Paulo: Instituto Ludwig von Mises Brasil, 2013.

BCB. Banco Central do Brasil. Histórico da Taxa de Juros. Disponível em: https://www.bcb.gov.br/Pec/Copom/ Port/taxaSelic.asp. Acesso em: 10 abril 2018.

BOETTKE, Peter. Summary of a Book from The Independet Institute - Living Economics Yesterday, Today and Tomorrow. Oakland: Independent Institute, 2012. Disponível em: http://www.independent.org/pdf/ book_summaries/livingeconomics_summary.pdf. Acesso em: 8 abril 2018.

BÖHM-BAWERK, Eugene Von. A Teoria da Exploração do Socialismo Comunismo. Rio de Janeiro: Instituto Liberal, 2013.

BÖHM-BAWERK, Eugene Von. Teoria positiva do capital. São Paulo: Nova Cultural, 1986.

BUTLER, Eamonn. A contribuição de Hayek às idéias políticas e econômicas de nosso tempo. Rio de Janeiro: Instituto Liberal, 1987.

BRUE, Stanley L. História do pensamento econômico. $6^{\circ}$ ed. São Paulo: Cengage Learning, 2016. 
DE SOTO, Jesus Huerta. A Escola Austríaca: mercado e criatividade empresarial. $2^{\circ}$ ed. São Paulo: Instituto Ludwig von Mises Brasil, 2010.

FED. Federal Reserve Bank of Saint Louis Basic Discount Rate. Disponível em: https://fred.stlouisfed.org/ graph/fredgraph.png?g=cdSb. Acesso em: 08 abril 2018.

FED. Effective Federal Funds Rate. Disponível em: https://fred.stlouisfed.org/graph/fredgraph.png?g=jcUs. Acesso em: 10 abril 2018.

FED. Monetary Policy Report to the Congress. Disponível em: https:/www.federalreserve.gov/boarddocs/ hh/2002/February/FullReport.pdf. Acesso em: 8 abril 2018.

HAYEK, Friedrich. Prices and Production and Other Works. Alabama: Ludwig von Mises Institute, 2008.

HAYEK, Friedrich. The Pure Theory of Capital. Londres: Routledge \& Kegan Paul LTD, 1950.

HAYEK, Friedrich August. The use of knowledge in society. The American economic review, v. 35, n. 4, p. 519-530, 1945.

IBGE. Expectativa de vida do brasileiro sobe para 75,8 anos. Disponível em: https://agenciadenoticias.ibge. gov.br/agencia-noticias/2012-agencia-de-noticias/noticias/18469-expectativa-de-vida-do-brasileiro-sobe-para75-8-anos.html. Acesso em: 3 mar 2018

IORIO, Ubiratan Jorge. Ação, tempo e conhecimento: A Escola Austríaca de economia. $2^{\circ}$ ed. São Paulo: Instituto Ludwig von Mises Brasil, 2011.

KIRZNER, Israel M. Austrian School of Economics. The New Palgrave: A Dictionary of Economics, v. 1. Macmillan, Londres, p. 145-157. 1987.

MENGER, Carl. Princípios de economia política. 3oe ed. São Paulo: Nova Cultural: 1988.

MISES, Ludwig von. O cálculo econômico sob o socialismo. $1^{\circ}$ ed. São Paulo: Instituto Ludwig Von Mises Brasil, 2012.

MORA, Monica. A evolução do Crédito no Brasil entre 2003 e 2010. Brasília: Instituto de Pesquisas Econômicas Aplicadas, 2015.

SAY, Jean-Baptiste. Tratado de economia política. São Paulo: Abril Cultural, 1983.

SMITH, Adam. A Riqueza das Nações: Investigação sobre sua natureza e suas causas. São Paulo: Nova Cultural, 1996.

SOROMENHO, Jorge Eduardo de Castro. Wicksell e teoria austríaca dos ciclos. Estudos Econômicos, v.25, p.77 - 113, 1995.

WAPSHOTT, Nicholas. Keynes vs Hayek - As Origens e a Herança do maior duelo econômico da História. Rio de Janeiro: Record, 2016.

WICKSELL, Knut. Lições de economia política. São Paulo: Nova Cultural, 1986. 